\title{
Mixed Infection of Cytomegalovirus and Pulmonary Nocardiosis Caused by Nocardia elegans Diagnosed Using Nanopore Sequencing Technology: A Case Report
}

\author{
Chie Watanabe ${ }^{1}$, Yoshifumi Kimizuka ${ }^{1}$, Yuji Fujikura ${ }^{1}$, Takaaki Hamamoto ${ }^{2}$, \\ Akira Watanabe ${ }^{3}$, Takashi Yaguchi ${ }^{3}$, Tomoya Sano ${ }^{1}$, Ryohei Suematsu ${ }^{1}$, Yoshiki Kato ${ }^{1}$, \\ Jun Miyata ${ }^{1}$, Susumu Matsukuma ${ }^{2,4}$ and Akihiko Kawana ${ }^{1}$
}

\begin{abstract}
:
A 69-year-old woman who had undergone renal transplantation and was receiving sulfamethoxazole/ trimethoprim (ST) developed pulmonary nocardiosis. To our knowledge, this is the first report of the identification of Nocardia elegans using nanopore sequencing, supported by $16 \mathrm{~S}$ rDNA capillary sequencing findings. Chest computed tomography performed after ST initiation revealed significant improvement of the pulmonary shadows compared to previous findings. We herein report the value of nanopore sequencing for rapid identification of rare pathogens, such as Nocardia elegans. Furthermore, our findings suggest that Nocardia may infect even patients receiving ST, which is currently the most effective prophylactic drug.
\end{abstract}

Key words: Nocardiosis, Nanopore sequencing, Immunocompromised, Organ transplantation

(Intern Med Advance Publication)

(DOI: 10.2169/internalmedicine.7639-21)

\section{Introduction}

Nocardia is a Gram-positive, beaded, weakly acid-fast, rod-shaped bacterium found ubiquitously in the soil, which can cause diseases of the lung, central nervous system, and skin in immunocompromised patients (1). More than 80 species have been identified, of which at least 33 are pathogenic in humans. The distribution of various species differs widely depending on the geographic location and generation (2).

Nanopore sequencing is a next-generation sequencing technology in which customized protein nanopores are used to determine nucleic acids and protein sequences (3). Recently, it has been shown to be useful in the detection of several bacterial species (4-7).

We herein report a case of pulmonary nocardiosis caused by Nocardia elegans in an immunocompromised patient who had undergone renal transplantation and was taking sulfamethoxazole/trimethoprim (ST) as prophylaxis for Pneumocystis jirovecii pneumonia (PCP). To our knowledge, this is the first report of the identification of Nocardia in clinical isolates using a nanopore sequencer, supported by findings of $16 \mathrm{~S}$ rDNA capillary sequencing performed using the classical method.

\section{Case Report}

A 69-year-old woman with IgA nephropathy underwent renal transplantation with a kidney donated by her husband. She developed an intermittent nocturnal fever approximately two months after transplantation. However, her diurnal body temperatures were normal. Two weeks after the fever onset, she visited our hospital for postoperative follow-up. She was receiving tacrolimus (3 mg/day), mycophenolate mofetil (1,500 mg/day), prednisolone (10 mg/day), and PCP prophy-

${ }^{1}$ Division of Infectious Diseases and Respiratory Medicine, Department of Internal Medicine, National Defense Medical College, Japan, ${ }^{2}$ Department of Laboratory Medicine, National Defense Medical College Hospital, Japan, ${ }^{3}$ Division of Bio-resources, Medical Mycology Research Center, Chiba University, Japan. and ${ }^{4}$ Department of Pathology and Laboratory Medicine, National Defense Medical College, Japan Received: March 26, 2021; Accepted: September 9, 2021; Advance Publication by J-STAGE: October 26, 2021 Correspondence to Dr. Yoshifumi Kimizuka, ykimizuka@ndmc.ac.jp 

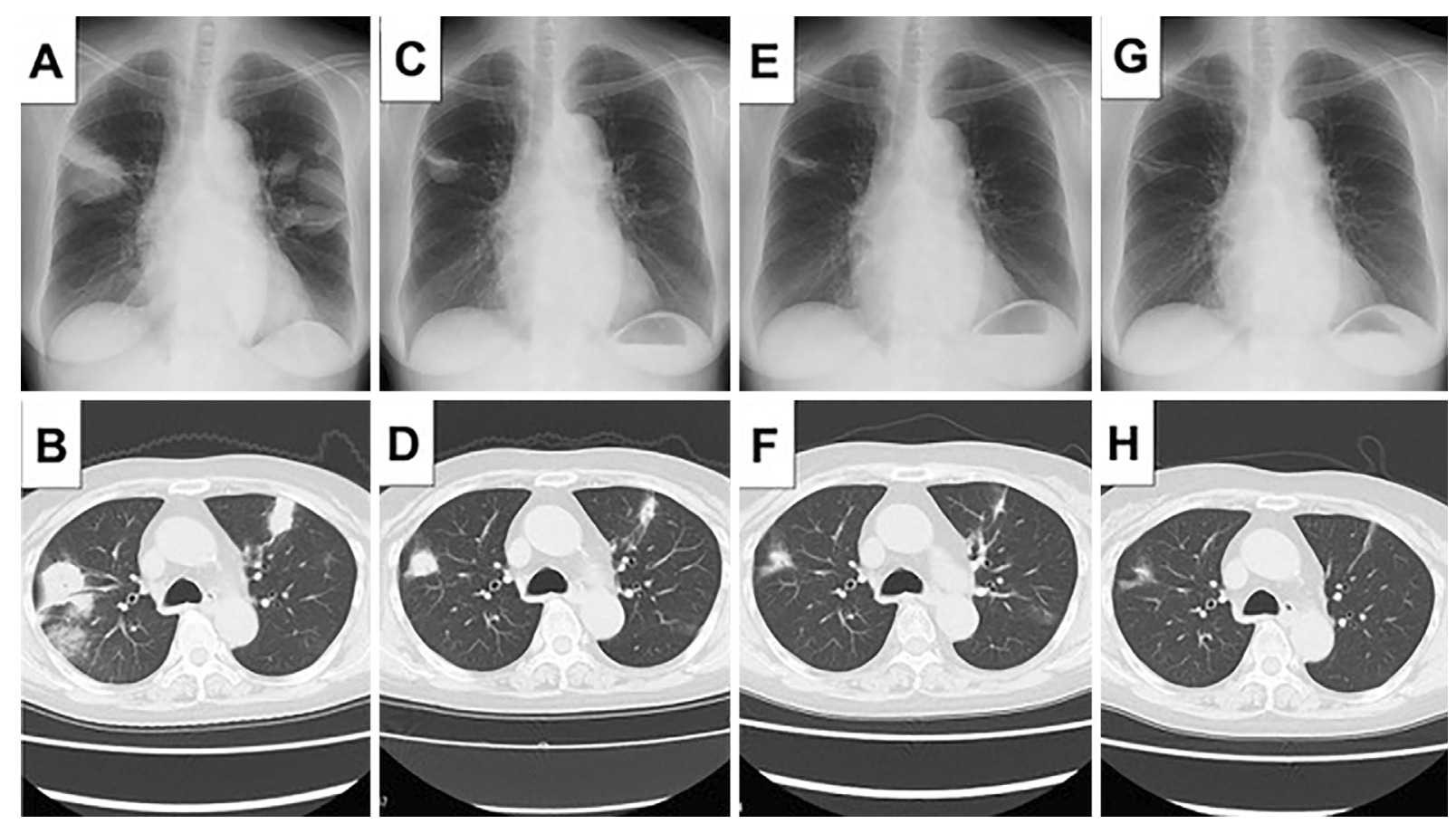

Figure. The patient's chest radiography and computed tomography (CT) findings. (A) Chest radiography and (B) chest CT findings on admission; (C) chest radiography and (D) chest CT after three weeks of treatment with ampicillin/sulbactam (AMPC/SBT); (E) chest radiography and (F) chest CT after three weeks of treatment with sulfamethoxazole/trimethoprim (ST); (G) chest radiography and (H) chest CT after nine weeks of treatment with ST. Multiple masses and nodules are seen predominantly in the upper lung fields and upper lobes, respectively, demonstrating a rim of ground-glass opacities on admission (A, B). After three weeks of treatment with AMPC/SBT, the masses and nodules had shrunk (C, D). The size of the nodules and masses reduced progressively, as seen via imaging examinations performed at three $(E, F)$ and nine $(G, H)$ weeks after ST initiation.

Table 1. Laboratory Findings of the Patient on Admission.

\begin{tabular}{|c|c|c|c|c|c|}
\hline \multicolumn{2}{|c|}{ Hematological parameters } & \multicolumn{4}{|c|}{ Serological and biochemical parameters } \\
\hline White blood cells & 9,800 cells $/ \mu \mathrm{L}$ & T-bil & $0.70 \mathrm{mg} / \mathrm{dL}$ & $\mathrm{T}_{\mathrm{T}} \mathrm{SPOT}{ }^{\circledR} . \mathrm{TB}$ & $(-)$ \\
\hline Neutrophil & $92.8 \%$ & AST & $36.0 \mathrm{IU} / \mathrm{L}$ & Anti-MAC antibody & $<0.5 \mathrm{IU} / \mathrm{mL}$ \\
\hline Lymphocyte & $3.9 \%$ & ALT & $32.0 \mathrm{IU} / \mathrm{L}$ & CEA & $2.7 \mathrm{ng} / \mathrm{mL}$ \\
\hline Basophil & $0.1 \%$ & LDH & $461 \mathrm{IU} / \mathrm{L}$ & CYFRA & $1.3 \mathrm{ng} / \mathrm{mL}$ \\
\hline Eosinophil & $0.1 \%$ & $\mathrm{TP}$ & $5.7 \mathrm{~g} / \mathrm{dL}$ & Pro-GRP & $44.4 \mathrm{pg} / \mathrm{mL}$ \\
\hline Monocyte & $3.1 \%$ & Alb & $2.9 \mathrm{~g} / \mathrm{dL}$ & sIL-2R & $1,850 \mathrm{IU} / \mathrm{mL}$ \\
\hline Red blood cells & $406 \times 10^{4}$ cells $/ \mu \mathrm{L}$ & BUN & $15.0 \mathrm{mg} / \mathrm{dL}$ & CMV pp65 antigenemia & $(+)$ \\
\hline Hemoglobin & $11.9 \mathrm{~g} / \mathrm{dL}$ & $\mathrm{Cr}$ & $0.91 \mathrm{mg} / \mathrm{dL}$ & $1 \rightarrow 3, \beta$-D glucan & $(-)$ \\
\hline Hematocrit & $35.6 \%$ & CRP & $15.1 \mathrm{mg} / \mathrm{dL}$ & & \\
\hline
\end{tabular}

Laboratory tests revealed elevated leukocyte and neutrophil counts and elevated levels of CRP, AST, and LDH. The CMV antigen was positive.

ALT: alanine transferase, AST: aspartate aminotransferase, BUN: blood urea nitrogen, CEA: carcinoembryonic antigen, CMV: cytomegalovirus, Cr: creatinine, CRP: C-reactive protein, CYFRA: cytokeratin 19 fragment, LDH: lactate dehydrogenase, MAC: Mycobacterium avium complex, Pro-GRP: pro-gastrin-releasing-peptide, sIL-2R: soluble interleukin-2 receptor, T-bil: total bilirubin, TB: tuberculosis, TP: total protein

laxis with oral ST (80 mg trimethoprim/400 mg sulfamethoxazole on alternate days). Chest radiography revealed multiple bilateral pulmonary nodules and consolidations that had not been present two months prior to the follow-up consultation (Figure A). Computed tomography (CT) revealed relatively well-defined nodules and cavitary masses in both lungs, surrounded by ground-glass opacities, which were located predominantly in the upper lobes (Figure B). Laboratory examinations showed an increase in the neutrophil count and C-reactive protein level and a positive cytomegalovirus (CMV) pp65 antigenemia assay; however, her $1 \rightarrow 3, \beta-D$ glucan level was within normal limits (Table 1).

Given the patient's immunocompromised state, she was 
admitted to the hospital immediately. Under suspicion of a bacterial or cytomegalovirus infection, she was placed simultaneously on oral ampicillin/sulbactam (AMPC/SBT; 750 $\mathrm{mg} /$ day) and valganciclovir (900 $\mathrm{mg} /$ day), respectively. Bronchoscopy was performed, and bronchoalveolar lavage culture of a specimen from the right B3 bronchus using sheep blood agar and chocolate agar revealed Nocardia sp. No other bacteria, fungi, or mycobacteria were isolated. A transbronchial biopsy of the right B3aii and B2bii was also performed. Although periodic acid-Schiff-positive microorganisms were not observed clearly, fine Gram-positive organisms with a branching structure were observed, suggesting the possibility of Nocardia. A pathological examination did not reveal any findings suggestive of viral infection. The patient became afebrile and was discharged on hospital day 9. We used nanopore sequencing (MinIONTM FLO-MIN107 R9.5 Version; Oxford Nanopore Technologies, Oxford, UK) technology and 16S rDNA capillary sequencing (ABI PRISM 3,130 and BigDye Terminator Cycle Sequencing Ready Reaction Kit, PE Applied Biosystems, Foster City, CA, USA) to identify the species (supplemental data). The nanopore and capillary sequence results confirmed $N$. elegans [mapped reads: 89.8\%, homology: 1,462/1,462 $(100 \%)]$. Brain magnetic resonance imaging revealed no findings suggestive of brain nocardiosis.

Based on the antimicrobial susceptibility test results (supplemental data), AMPC/SBC was discontinued, and ST (treatment dose; $15 \mathrm{mg} / \mathrm{kg}$ trimethoprim), which is a more appropriate treatment for nocardiosis, was initiated. Eighteen days after treatment initiation, she developed neutropenia, which was considered an adverse effect of ST. As a result, ST was discontinued for 1 week and reinitiated at half of the initial dose $(7.5 \mathrm{mg} / \mathrm{kg}$ trimethoprim) after neutropenia improved. Since then, her white blood cell count has been maintained at $>2,800$ cells $/ \mu L$. Her serum CMV pp65 antigenemia was negative after 11 weeks of valganciclovir therapy. Follow-up CT performed three and nine weeks after ST initiation revealed the gradual improvement in pulmonary shadows (Figure F-H). ST treatment was completed 12 months after its initiation, and no recurrence of abnormal pulmonary shadows has been noted since then.

\section{Discussion}

We encountered a case of pulmonary $N$. elegans infection in a patient who was receiving ST as prophylaxis for PCP after renal transplantation. Although the epidemiology of Nocardia sp. infection, which is pathogenic to humans, varies with the geographic region and generation, the $N$. asteroides complex that includes $N$. farcinica and $N$. nova is frequently isolated in pulmonary nocardiosis (8-10). N. elegans, which belongs to the $N$. vaccinii clade, is a rare species isolated in nNocardial infections; only 14 cases have been reported previously (Table 2). Relevant studies, including our own, have included a higher proportion of men than women $(8 / 14$; the sex of 2 patients was unknown), with a mean patient age of $52.0 \pm 19.5$ (range: $12-73$ ) years old. The most frequent infection site was the lungs (10/14), and only two cases of central nervous system infection were reported. The cases occurred mainly in East Asian countries, including Japan, South Korea, China, and Taiwan. Only our patient and the patient described by Park et al. (13) had been receiving ST as PCP prophylaxis after renal transplantation prior to the diagnosis. The patient described by Ueda et al. (18) had been receiving prednisolone for systemic lupus erythematosus.

The recently reported incidence of nocardial infection after renal transplantation was $0.4 \%-1.3 \%$, of which $65.2 \%$ were pulmonary nocardiosis cases (24). To our knowledge, only one previous case of $N$. elegans infection has been reported in a patient after renal transplantation. The Kidney Disease Improving Global Outcomes (KDIGO) clinical practice guidelines recommend that all kidney transplant recipients receive ST as PCP prophylaxis after transplantation (25); however, some cases of nocardial infection have been reported, despite the administration of prophylactic ST. In a previous report, ST resistance was related to the onset of breakthrough nocardiosis (13); however, our patient did not present with ST resistance, which suggests that the prophylactic dose of ST could not prevent the onset of breakthrough nocardiosis completely due to the presence of multiple risk factors in the host.

Furthermore, in another previous study of allogeneic hematopoietic stem cell transplant recipients, the incidence of nocardiosis increased after ST was replaced by atovaquone for PCP prophylaxis (26). Currently, ST is the most suitable prophylactic drug for nocardiosis after renal transplantation.

In addition, an ST treatment course of at least six months is recommended, even for immunocompetent patients (27). Our patient had a relatively good response to the therapeutic dose of ST. Therefore, the treatment was continued for 12 months, considering the patient's immunocompromised state.

Nocardia has traditionally been classified morphologically, but the identification of specific species is a difficult task requiring specialized knowledge. The $16 \mathrm{~S}$ rRNA method, which is conservative and species-specific, is often used for accurate taxonomic identification (28). Although capillary sequencing is the primary method for genetic characterization of Nocardia spp., to our knowledge, this is the first time that nanopore sequencing has been successfully used to identify $N$. elegans in a clinical isolate. So far, this technology has also been used for specific tasks, including Zika virus identification (5), identification of liver abscesscausing bacteria (6), and detection of human papillomaviruses in the cervix microbiome (7). Nanopore sequencing is a simple method that may contribute to the rapid identification of bacterial species in clinical practice, even in the identification of rare species. In addition, because nanopore sequencing is used for antimicrobial resistance gene detection (29), it may be used for drug resistance screening.

Several limitations associated with the present study warrant mention. First, the effectiveness of nanopore sequencing 
Table 2. Clinical Features and Outcomes of Nocardia Elegans infection in the Present Case and Previously Reported Cases.

\begin{tabular}{|c|c|c|c|c|c|c|c|c|}
\hline No. & References & Site of isolate & $\begin{array}{l}\text { Clinical manifestation/ } \\
\text { site }\end{array}$ & Background & $\begin{array}{l}\text { Prophylaxis } \\
\text { with ST }\end{array}$ & Country & Treatment & Outcome \\
\hline 1 & (11) & Sputum & Pulmonary infection & $\ldots$ & $\ldots$ & Germany & $\ldots$ & $\cdots$ \\
\hline 2 & (12) & $\ldots$ & Bronchitis & $\ldots$ & $\ldots$ & Japan & $\ldots$ & $\ldots$ \\
\hline 3 & (13) & Punctured pus & Lung abscess & $\begin{array}{c}\text { Kidney } \\
\text { transplantation }\end{array}$ & $\mathrm{Y}$ & Korea & $\begin{array}{l}\mathrm{ST}+\mathrm{IMP} / \mathrm{CS} \Rightarrow \\
\mathrm{AMPC} / \mathrm{CVA}\end{array}$ & Improved \\
\hline 4 & (14) & Sputum & Pulmonary infection & Cystic fibrosis & $\ldots$ & Spain & MEPM+TOB & Improved \\
\hline 5 & (15) & $\ldots$ & Pulmonary infection & Dermatomyositis & $\mathrm{N}$ & Taiwan & $\ldots$ & $\ldots$ \\
\hline 6 & (16) & Synovial fluid & Purulent arthritis & $\cdots$ & $\ldots$ & Japan & $\ldots$ & $\ldots$ \\
\hline 7 & (17) & Sputum & Pulmonary infection & Still's disease & $\ldots$ & Japan & IMP/CS+AMK & Improved \\
\hline 8 & (18) & Sputum & Pulmonary+brain & $\begin{array}{l}\text { Systemic lupus } \\
\text { erythematosus }\end{array}$ & $\mathrm{Y}$ & Japan & $\mathrm{ST}+\mathrm{CAM}$ & Improved \\
\hline 9 & (19) & $\begin{array}{l}\text { Skin abscesses } \\
\text { and vitreous } \\
\text { fluid }\end{array}$ & Pulmonary+eye+skin & $\begin{array}{l}\text { Rheumatoid } \\
\text { arthritis }\end{array}$ & $\mathrm{N}$ & Japan & $\begin{array}{l}\mathrm{CFPM} \Rightarrow \mathrm{ST} \Rightarrow \\
\mathrm{IMP} / \mathrm{CS}+\mathrm{MINO}\end{array}$ & $\begin{array}{l}\text { Survived but } \\
\text { lost vision + } \\
\text { resistant }\end{array}$ \\
\hline 10 & (20) & $\begin{array}{l}\text { Sputum and } \\
\text { skin lesion }\end{array}$ & Pulmonary+skin & Diabetes mellitus & $\mathrm{N}$ & China & Penicillin+DOXY+ST & Improved \\
\hline 11 & (21) & $\begin{array}{l}\text { Punctured pus } \\
\text { and central } \\
\text { nervous system }\end{array}$ & Pulmonary+renal+brain & Renal tumour & $\ldots$ & $\begin{array}{l}\text { Mali/ } \\
\text { France }\end{array}$ & $\begin{array}{c}\mathrm{PIPC} / \mathrm{TAZ}+\mathrm{AMK} \Rightarrow \\
\mathrm{IMP} / \mathrm{CS}+\mathrm{CPFX}\end{array}$ & $\begin{array}{c}\text { Died }+ \\
\text { resistant }\end{array}$ \\
\hline 12 & $(22)$ & $\begin{array}{l}\text { Bronchial } \\
\text { lavage }\end{array}$ & Pulmonary & $\begin{array}{l}\text { Systemic lupus } \\
\text { erythematosus }\end{array}$ & $\ldots$ & Japan & ST & Improved \\
\hline 13 & $(23)$ & Punctured pus & $\begin{array}{l}\text { Pulmonary+subcostal } \\
\text { muscle }\end{array}$ & $\begin{array}{l}\text { Hematopoietic } \\
\text { stem cell } \\
\text { transplantation }\end{array}$ & $\mathrm{N}$ & Japan & CAM & Improved \\
\hline 14 & $\begin{array}{l}\text { Present } \\
\text { case }\end{array}$ & $\begin{array}{l}\text { Transbronchial } \\
\text { lung biopsy }\end{array}$ & Pulmonary & $\begin{array}{c}\text { Kidney } \\
\text { transplantation }\end{array}$ & $\mathrm{Y}$ & Japan & $\mathrm{ABPC} / \mathrm{SBT} \Rightarrow \mathrm{ST}$ & Improved \\
\hline
\end{tabular}

ABPC/SBT: ampicillin/sulbactam, AMK: amikacin, AMPC/CVA: amoxicillin/clavulanate, CAM: clarithromycin, CFPM: cefepime, CPFX: ciprofloxacin, DOXY: doxycycline, IMP/CS: imipenem/cilastatin, MEPM: meropenem, MINO: minocycline, N: no, PIPC/TAZ: tazobactam/piperacillin, ST: trimethoprim/ sulphamethoxazole, Y: yes

in gene extraction is limited. The accuracy may be improved by the simultaneous use of $16 \mathrm{~S}$ rRNA amplification or by increasing the amount of nucleic acid extracted from bacterial samples. Second, a bacterial co-infection could not be excluded because empirical treatment with AMPC/SBT was administered. However, our patient was immunocompromised after renal transplantation and needed empiric antimicrobial therapy. Third, CMV pneumonia and antiviral treatment may have affected the progression of pulmonary shadows. However, while bronchoscopy detected Nocardia in the area of abnormal shadows, no microscopic morphological changes suggestive of a viral infection were observed. Therefore, we believe that our patient mainly had a nocardial infection.

\section{Conclusion}

We herein report a rare case of pulmonary infection caused by $N$. elegans in a patient who was immunosuppressed after undergoing renal transplantation. The bacterial species was rapidly identified using nanopore sequencing. It is important to note that Nocardia may infect patients receiving ST, even though ST is considered the most effective prophylactic drug.

The authors state that they have no Conflict of Interest (COI).

\section{Acknowledgement}

We are grateful to H. Sugiura (Department of Radiology, National Defense Medical College) for the helpful suggestions and advice provided during this project.

The clinical isolate was preserved as IFM 12178 at the Medical Mycology Research Center (MMRC), Chiba University, through the National Bio-Resource Project, Japan.

\section{Funding sources}

This research did not receive any specific grant from funding agencies in the public, commercial, or not-for-profit sectors.

\section{Disclosure}

None of the authors have any conflicts of interest or financial ties to disclose.

\section{Ethical approval}

This study was approved by the National Defense Medical College Review Committee (4349).

\section{Consent for publication}

Written informed consent was obtained from the patient for the publication of this case report and any accompanying images. A copy of the written consent is available for review. 


\section{References}

1. Sorrell TC, Mitchell DH, Iredell JR, et al. Nocardia Species. In: Principles and Practice of Infectious Diseases. 7th ed. Mandell GL, Bennett JE, Dolin R, Eds. Churchill Livingstone Elsevier, Philadelpha, 2010: 2853-2863.

2. Brown-Elliott BA, Brown JM, Conville PS, Wallace RJ Jr. Clinical and laboratory features of the Nocardia spp. based on current molecular taxonomy. Clin Microbiol Rev 19: 259-282, 2006.

3. Kilianski A, Haas JL, Corriveau EJ, et al. Bacterial and viral identification and differentiation by amplicon sequencing on the Minion nanopore sequencer. GigaScience 4: 12, 2015.

4. Niedringhaus TP, Milanova D, Kerby MB, Snyder MP, Barron AE. Landscape of next-generation sequencing technologies. Anal Chem 83: 4327-4341, 2011.

5. Quick J, Grubaugh ND, Pullan ST, et al. Multiplex PCR method for MinION and Illumina sequencing of Zika and other virus genomes directly from clinical samples. Nat Protoc 12: 12611276, 2017.

6. Gong L, Huang YT, Wong CH, et al. Culture-independent analysis of liver abscess using nanopore sequencing. PLoS ONE 13: e 0190853, 2018.

7. Quan L, Dong R, Yang W, et al. Simultaneous detection and comprehensive analysis of HPV and microbiome status of a cervical liquid-based cytology sample using nanopore MinION sequencing. Sci Rep 9: 19337, 2019.

8. Kageyama A, Yazawa K, Ishikawa J, et al. Nocardial infections in Japan from 1992 to 2001, including the first report of infection by Nocardia transvalensis. Eur J Epidemiol 19: 383-389, 2004.

9. Minero VM, Marin M, Cercenado E, et al. Nocardiosis at the turn of the century. Medicine (Baltimore) 88: 250-261, 2009.

10. Conville PS, Brown-Elliott BA, Smith T, Zelazny AM. The complexities of Nocardia taxonomy and identification. J Clinical Microbiol 56: e01419-17, 2018.

11. Yassin AF, Brenner S. Nocardia elegans sp. nov., a member of the Nocardia vaccinii clade isolated from sputum. Int J Syst Evol Microbiol 55: 1505-1509, 2005.

12. Watanabe K, Shinagawa M, Amishima M, et al. Jpn J Med Mycol 47: 87-89, 2006.

13. Park KH, Ko SY, Oh R, et al. A case of lung abscess caused by Nocardia elegans in a kidney transplantation recipient. Infect Chemother 40: 116-120, 2008 (in Korean).

14. Barrio MI, Martínez MC, Prados C, et al. Isolation of Nocardia Species in Patients With Cystic Fibrosis. Arch Bronconeumol 44: 109-112, 2008.

15. Liu WL, Lai CC, Ko WC, et al. Clinical and microbiological characteristics of infections caused by various Nocardia species in Taiwan: a multicenter study from 1998 to 2010. Eur J Clin Microbiol Infect Dis 30: 1341-1347, 2011.

16. Masaki T, Ohkusu K, Ezaki T, Miyamoto H, et al. Nocardia elegans infection involving purulent arthritis in humans. J Infect Che- mother 18: 386-389, 2012.

17. Ooi Y, Shiba H, Nagai K, et al. Lung Nocardia elegans Infection Diagnosed on Matrix-assisted Laser Desorption Ionization-time of Flight Mass Spectrometry (MALDI-TOF MS). Intern Med 53: 2111-2113, 2014.

18. Ueda $\mathrm{Y}$, Yamamoto $\mathrm{K}$, Watanabe $\mathrm{K}$, Yamashita H, Ohmagari N, Mimori A. Obstructive pneumonia and brain abscess due to Nocardia elegans in a patient with systemic lupus erythematosus. Kansenshogaku Zasshi (The Journal of The Japanese Association for Infectious Diseases) 88: 282-287, 2014 (in Japanese).

19. Nakamura I, Nagakura T, Fujita H, Fukusima S, Gonoi T. Nocardia elegans infection: a case report and literature review. Int J Infect Dis 54: 15-17, 2017.

20. You Y, Chen W, Zhong B, Song Z, Yang X. Disseminated nocardiosis caused by Nocardia elegans: a case report and review of the literature. Infection 46: 705-710, 2018.

21. Senard O, Blanot S, Jouvion G, et al. Fulminant Nocardiosis Due to a Multidrug-Resistant Isolate in a 12-Year-Old Immunocompetent Child. Pediatrics 141: e20163131, 2018.

22. Kobashi Y, Kittaka M, Shirai R, Kato S, Oka M. Clinical analysis of pulmonary nocardiosis in tertiary hospital. Am J Infect Dis 14: 56060, 2018.

23. Tajima K, Okuyama S, Terada T, et al. Clarithromycin as an alternative and prophylactic agent in a hematopoietic stem cell transplantation patient. Am J Case Rep 22: e931731, 2021.

24. Yu X, Han F, Wu J, et al. Nocardia infection in kidney transplant recipients: case report and analysis of 66 published cases. Transpl Infect 13: 385-391, 2011.

25. Kidney Disease; Improving Global Outcomes (KDIGO) Transplant Work Group. KDIGO clinical practice guideline for the care of kidney transplant recipients. Am J Transplant 9: S1-S155, 2009.

26. Molina A, Winston DJ, Pan D, Schiller GJ. Increased incidence of nocardial infections in an era of atovaquone prophylaxis in allogeneic hematopoietic stem cell transplant recipients. Biol Blood Marrow Transplant 24: 1715-1720, 2018.

27. Sorrell TC, Mittchell DH, Iredell JR. Nocardia Species. In: Principles and Practice of Infectious Diseases. Mandell GL, Bennet JE, Dolon R, Eds. Churchill Livingstone, USA, 2018: 2916-2924.

28. Yarza P, Yilmaz P, Pruesse E, et al. Uniting the classification of cultured and uncultured bacteria and archaea using 16S rRNA gene sequences. Nat Rev Microbiol 12: 635-645, 2014.

29. Lemon JK, Khil PP, Frank KM, Dekker JP. Rapid nanopore sequencing of plasmids and resistance gene detection in clinical isolates. J Clin Microbiol 55: 3530-3543, 2017.

The Internal Medicine is an Open Access journal distributed under the Creative Commons Attribution-NonCommercial-NoDerivatives 4.0 International License. To view the details of this license, please visit (https://creativecommons.org/licenses/ by-nc-nd/4.0/).

\section{(C) The Japanese Society of Internal Medicine Intern Med Advance Publication}

